\title{
Survivorship of Anopheles gambiae sensu lato in irrigated sugarcane plantation scheme in Ethiopia
}

\author{
Dawit Hawaria ${ }^{1,4,6 *}$, Solomon Kibret ${ }^{3}$, Assalif Demissew² ${ }^{2}$ Arega Tsegaye ${ }^{5,6}$, Denekew Bitew $^{7}$, Guiyun Yan ${ }^{3}$ \\ and Delenasaw Yewhalaw ${ }^{4,6}$
}

\begin{abstract}
Background: To ensure food security, sub-Saharan Africa has initiated massive water resource development projects, such as irrigated agriculture, in recent years. However, such environmental modifications affect the survivorship and development of mosquitoes, which are vectors of different diseases. This study aimed at determining the effects of irrigation practices on development and survivorship of Anopheles gambiae s.l. in Ethiopia.

Methods: A life table experiment was conducted to examine the effect of environmental modification on survivorship of both immature and adult An. gambiae s.l. in irrigated and non-irrigated areas. The pupation rate and development time of the immatures and adult longevity and fecundity were compared between the two settings.

Results: The estimated mean survival time of female An. gambiae s.l. in the irrigated and non-irrigated areas was 37.9 and 31.3 days, respectively. A survival analysis showed that adult females of An. gambiae s.l. placed in an irrigated area lived significantly longer than those in a non-irrigated area $(x 2=18.3, d f=1, P<0.001)$, and An. gambiae s.l. females lived significantly longer than males in both areas $(P<0.001)$.

Conclusions: Adult An. gambiae s.l. survivorship was found to be enhanced in the irrigated area compared to nonirrigated area. Longer survival of adult mosquitoes in irrigated areas could have important implications for vectorial capacity and hence malaria transmission.
\end{abstract}

Keywords: Malaria, Survivorship, Anopheles gambiae s.l., Land cover, Sugarcane, Irrigation, Ethiopia

\section{Background}

Mosquito survivorship is an important factor that determines vectorial capacity and malaria transmission potential [1]. For example, the Anopheles mosquito needs to survive beyond the extrinsic incubation period of the Plasmodium parasites to be able to transmit malaria; the longer a mosquito lives, the higher the number of bites it may inflict [2]. The malaria vector immature survivorship and enhanced larval-to-pupal development rate increase adult population density, which in turn affects

\footnotetext{
*Correspondence: hawaria.dawit@gmail.com

${ }^{1}$ Yirgalem Hospital Medical College, Yirgalem, Ethiopia

Full list of author information is available at the end of the article
}

the vectorial capacity of mosquito populations in a particular setting $[3,4]$.

Mosquito survivorship and development may be affected by environmental factors. Temperature (both water and ambient), relative humidity, rainfall, and nutrient availability are key environmental factors governing the dynamics of malaria vectors including development and survival [4-6]. These factors can be strongly influenced by variation in land use and land cover change such as the vegetation cover, landscape, and distance to water bodies [7, 8]. Zhong et al. [9] and Wang et al. [10] reported enhanced survivorship and development of both adults and larvae of An. sinensis and An. minimus, major malaria vectors in China with higher ambient temperature due to 
land use and land cover change. Fine-scale variation in the microclimate across different landscapes shapes variation in mosquito population dynamics [11].

In an effort to avert poverty, developing countries have been implementing water resource development projects such as hydropower dams and agricultural development irrigation schemes [7, 12, 13]. Previous studies indicated that such changes in land use and land cover have increased malaria transmission by proliferating vector breeding sites and changing the microclimate that governs the dynamics of the vectors [7, 13-19].

Ethiopia, a country where $>75 \%$ of the total area is malarious [20], has been experiencing a massive change in land use and land cover through water resource development projects including irrigation schemes and hydroelectric power dam projects [21]. The Arjo-Dedessa sugar development project site is among the mega-irrigation schemes with an irrigated area covering approximately 4000 ha, with future expansion plans for 80,000 ha, to supply a state-owned sugar factory [22]. The area has historically been a wildlife sanctuary. Long ago, the government settled residents evacuating from other drought-prone areas of the country to establish their lives through subsistence farming. The area is endemic to malaria [22]. A recent entomological study in the same study site demonstrated higher malaria vector breeding habitat diversity, larval occurrence, and abundance in the irrigated area than in the non-irrigated area [23]. However, how this massive environmental modification has been influencing the survivorship and development of major malaria vectors in the area is not yet understood. Understanding malaria vector bionomics in relation to environmental modification helps to model malaria transmission for better evidence-based interventions, which will have a profound effect on realizing the country's malaria elimination goal by 2030 [24]. We hypothesized that land use and land cover changes, especially massive irrigated agricultural areas, alter the survivorship and development of malaria vectors in the areas.

Therefore, the objective of this study was to determine the effects of an irrigated sugarcane plantation scheme on the development and survivorship of An. gambiae s.l. Knowledge of the vector response to environmental modification will give a better understanding of malaria transmission dynamics, which is useful for predicting the impact of environmental modification on malaria transmission intensity and will help establish tailored vector control interventions.

\section{Methods}

\section{Study setting and period}

The study was conducted at the Arjo-Dedessa irrigation development site $\left(8^{\circ} 41^{\prime} 60^{\prime \prime} \mathrm{N}, 36^{\circ} 23^{\prime} 60^{\prime \prime} \mathrm{E}\right)$, Southwest
Ethiopia, from August to October 2019. Extensive irrigated agriculture represents the most important environmental change in the area. The irrigation development areas were covered with massive irrigated sugarcane plantation (hereafter irrigated area), whereas the surrounding areas were covered with other non-irrigated field crops commonly cultivated in the area (hereafter non-irrigated area). Local communities in the area depend on subsistence farming with practicing smallholder non-irrigated cultivation of mixed crops and cereals. The common crops and fruit trees grown in the area include corn, maize, peanut, sorghum, rice, wheat, coffee, and mango.

\section{Site selection}

For the study, we selected two land use and land cover types: areas covered with irrigated sugarcane plantation and areas covered with other field crops common in the area.

\section{Anopheles gambiae s.l. immature survivorship Adult mosquito collection and larva hatching}

Blood-engorged An. gambiae s.l. were collected from inside houses and animal shelters in the study area using a mouth aspirator. All collected mosquitoes were kept in paper cages at a field insectary. An oviposition substrate of Petri dishes lined with filter paper disks on moistened cotton wool was kept inside each cage for egg laying. Collected eggs were allowed to hatch, and newly hatched first instar larvae were used for the experiment.

\section{Experiment}

Plastic washbasins $(34 \mathrm{~cm} \times 14 \mathrm{~cm})$ were used to imitate natural larval breeding habitats. The washbasins were exposed to an outdoor environment for a week prior to the initiation of the experiment for acclimatization. Then, $2 \mathrm{l}$ of rainwater and $1 \mathrm{~kg}$ of soil from the same area were added to each washbasin and left for a day. The washbasins were kept at each selected site in the two different areas (irrigated and non-irrigated areas). Fifty newly emerged first instar An. gambiae s.l. larvae were transferred into each washbasin with eight replicates for each site. The water level in the washbasins was checked daily and maintained by adding water if needed. To prevent other insects from invading the washbasins or other mosquitoes from laying eggs, the washbasins were placed inside an insect-proof $61 \times 61 \times 61 \mathrm{~cm}^{3}$ BugDorm tent [BioQuip, Rancho Dominguez, (BD2120), CA, USA] (Fig. 1). All sides of the BugDorm tent were made of clear polyester netting materials so that sunlight was not blocked. The homogeneity of washbasins had an advantage over the natural habitats, which were highly variable in habitat size, larval food conditions (e.g. organic 


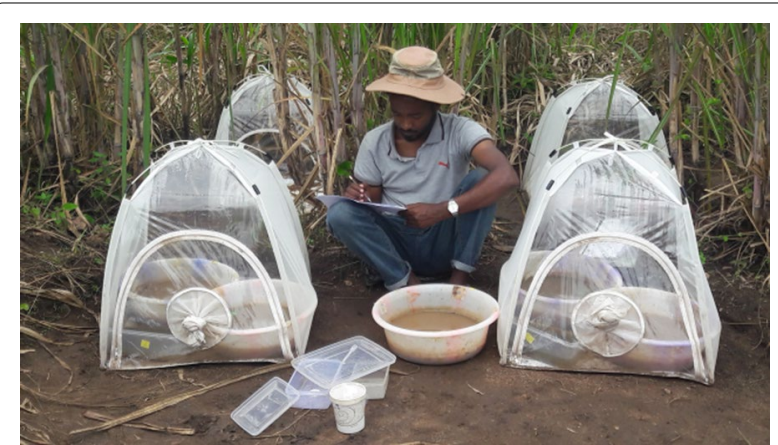

Fig. 1 Insect-proof BugDorm tent with washbasins inside

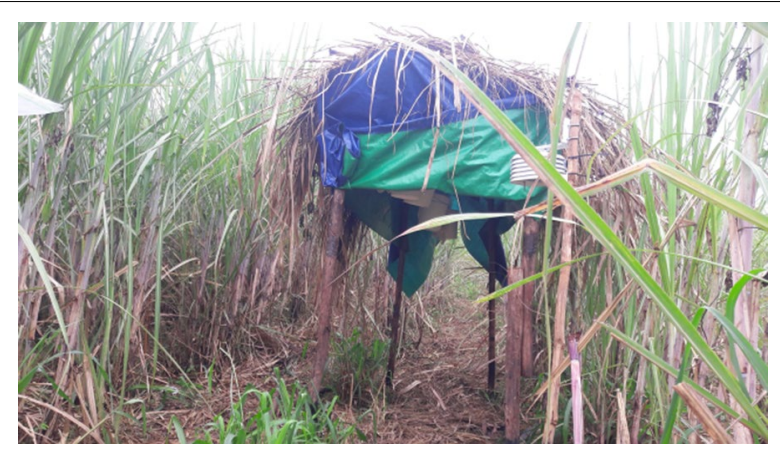

Fig. 2 Roof structure from which cages with adult An. gambiae s.l mosquitoes were suspended

matter), vegetation coverage, light shade, competitors, and predators. Each day the number of surviving larvae, their developmental stage, and mortality were recorded. Pupae were counted and removed daily. Removed pupae were collected in a waterproof paper cup for adult emergence.

\section{Anopheles gambiae s.l. adult survivorship experiment}

In this experiment, An. gambiae s.l. adults that emerged from the larval survivorship experiments were used. Within $24 \mathrm{~h}$ post-emergence, 25 female and 25 male adult mosquitoes were transferred into a paper cage $(21.5 \mathrm{~cm}$ $\times 9 \mathrm{~cm}$ ). The cages were covered with nylon mesh to prevent mosquito escape. Then, the cages were placed in the irrigated and non-irrigated areas in five replicates for each site. Mosquito cages were hung from the roof structures of small temporary shelters ( $2 \mathrm{~m}$ high) constructed for the purpose of the experiment for rain protection (Fig. 2). To prevent ants from reaching and scavenging the mosquitoes, grease was applied to the suspension twines. Mosquitoes were provided with $10 \%$ sucrose solution and a bloodmeal from a human arm (DH) every other day for $20 \mathrm{~min}$. An oviposition substrate consisting of a Petri dish lined with a filter paper disk on moistened cotton wool was placed for egg-laying. The oviposition substrate in each cage was examined daily for the presence of eggs, and the number of eggs laid was examined under a dissecting microscope, counted, and recorded. The cages were examined daily for the numbers of surviving and dead mosquitoes. The dead mosquitoes were recorded and removed from the cage daily.

\section{Microclimate data collection}

For the larval survivorship experiment, a HOBO data logger (Onset Computer Corp., MX2202, Bourne, MA) was placed in each washbasin, $1 \mathrm{~cm}$ below the water surface, and then hourly water temperature and light intensity were recorded for the entire duration of the experiment. For the adult survivorship experiment, HOBO data loggers (Onset Computer Corp., MX2301) were kept close to the experiment set-up $2 \mathrm{~m}$ above ground, and then the hourly ambient temperature and relative humidity were recorded for the entire duration of the experiment.

\section{Data analysis}

The pupation rate of $A n$. gambiae s.l. larvae was calculated as the proportion of first instar larvae that developed into pupae. Mean larval-to-pupal development time was calculated. Stage-specific larval development time and mortality rate were calculated. Kaplan-Meier survival analysis was performed to determine the variation in mean daily survivorship of mosquitoes placed in two different land use and land cover areas. A log-rank test was used to determine the difference between two survival curves. Daily average, minimum, and maximum temperatures, relative humidity, and light intensity were calculated from the hourly record data to determine the effect of different land uses and land covers on the microclimate of local niches where mosquitoes were tested for survivorship. Independent sample t-test was performed to compare mean pupation rate, development time, and microclimate differences across irrigated and other nonirrigated crop areas. The analysis was performed using IMB SPSS Statistics 25, R 3.5.2, and Microsoft Excel 2016.

\section{Results}

Around 300 blood-engorged An. gambiae s.l. were collected from indoors and outdoors (cow shelter) using mechanical mouth aspirators. Eight hundred first instar larvae hatched from the field-collected mosquitoes were used for the experiments in irrigated and non-irrigated areas, 400 each.

\section{Developmental time and survivorship of An. gambiae s.I. larvae}

The proportion of larvae that completed development from first instar larvae to pupae in the irrigated area and 
non-irrigated area was $79.4 \%$ (95\% CI $0.66-0.93)$ and $84.5 \%$ (95\% CI 0.77-0.92), respectively. Statistical analysis showed that the difference in pupation rate was not significant between the irrigated and non-irrigated area $(t=$ $2.22, P=0.208$ ) (Fig. 3). The mean larval-to-adult development time of An. gambiae s.l. larvae in the irrigated and non-irrigated areas was 12.5 and 12, respectively. Similarly, the median larvae-to-pupae development time in the irrigated area was 12.5 (95\% CI 10.2-14.8) days and in the non-irrigated area 12 (95\% CI 9.7-14.2) days (Table 1). Kaplan-Meier survival analysis showed no significant difference in larval survivorship between the two areas $\left(\chi^{2}=2.62, P=0.106\right)$ (Fig. 4).

Stage-specific survival and mortality analysis showed a slight increment in the mortality rate as the larvae developed to proceeding larval instars in both settings (Table 2).

\section{Adult An. gambiae s.l. survivorship and fecundity}

Survival analysis showed that female An. gambiae s.l. placed in the irrigated area survived significantly longer than those in the non-irrigated area $\left(x^{2}=18.3, d f=1, P\right.$ $<0.001$ ) (Fig. 5).

The estimated mean survival time of female An. gambiae s.l. in irrigated and non-irrigated areas was 37.9 and 31.3 days, respectively (Table 3 ). Again, female mosquitoes showed the higher median survival period (41.0 days) in irrigated than non-irrigated area (31.0 days). A similar result was found in that male An. gambiae s.l. survived a longer period in the irrigated than non-irrigated area $\left(\chi^{2}=23.1, d f=1, P<0.001\right)$ with mean survival time of 31.8 and 24.2 days, respectively (Table 3 ). The median survival period for male mosquitoes was 33.0 days in

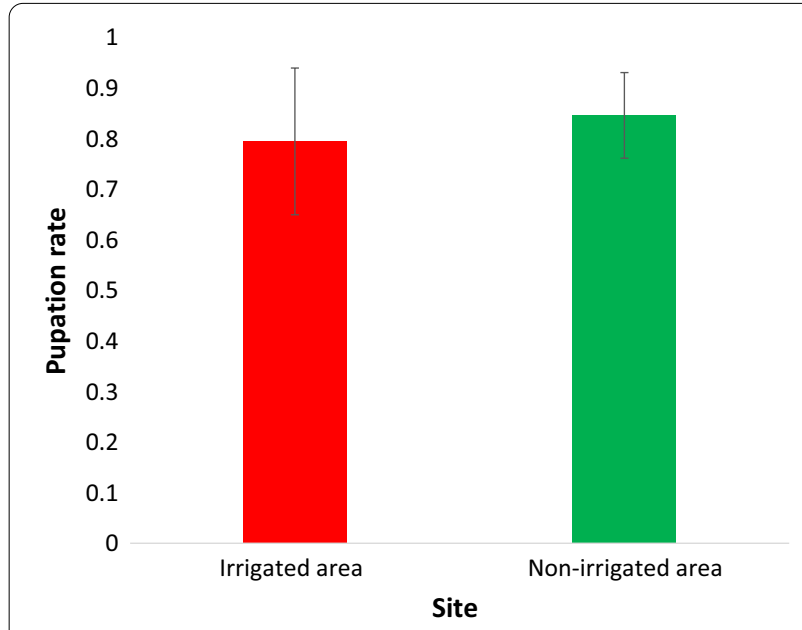

Fig. 3 Pupation rate of An. gambiae s.l. larvae in irrigated and non-irrigated areas, Southwest Ethiopia, 2019
Table 1 Means and medians of survival time for immature An. gambiae s.l. in irrigated and non-irrigated areas, Southwest Ethiopia, 2019

\begin{tabular}{llllll}
\hline Site & $\begin{array}{l}\text { Mean with } \\
95 \% \mathrm{Cl}\end{array}$ & $\begin{array}{l}\text { Median with } \\
95 \% \mathrm{Cl}\end{array}$ & \multicolumn{2}{l}{$\begin{array}{l}\text { Overall } \\
\text { comparisons }\end{array}$} \\
\hline $\begin{array}{l}\text { Irrigated area } \\
\begin{array}{l}\text { Non-irrigated } \\
\text { area }\end{array}\end{array}$ & $12.5(10.3-14.4)$ & $12.5(10.2-14.8)$ & $x^{2}$ & $d f$ & $P$-value \\
\end{tabular}

the irrigated area and 24.0 days in the non-irrigated area (Table 1). Male An. gambiae s.l. survival was decreased compared to that of females in both the irrigated $\left(\chi^{2}=\right.$ 14.9, $P<0.001)$ and non-irrigated areas $\left(\chi^{2}=20.9, P<\right.$ 0.001 ) (Additional file 1).

Of 7737 eggs laid by the female mosquitoes throughout the experiment period, 5125 (66.2\%) were from the mosquitoes placed in the irrigated area and 2612 (33.8\%) were from mosquitoes in the non-irrigated area. The study showed that fecundity of mosquitoes was $96.2 \%$ higher in the irrigated area (80 eggs/day) than in the nonirrigated area (average 33 eggs/day). The mean number of eggs laid was (41 \pm SE 11.63 eggs/mosquito) and (21 $\pm 5.61 \mathrm{eggs} / \mathrm{mosquito})$ in the irrigated and non-irrigated area, respectively. Statistical analysis showed that the difference in fecundity was significant between the irrigated and non-irrigated area $(t=2.83, P=0.002)$ (Additional file 2).

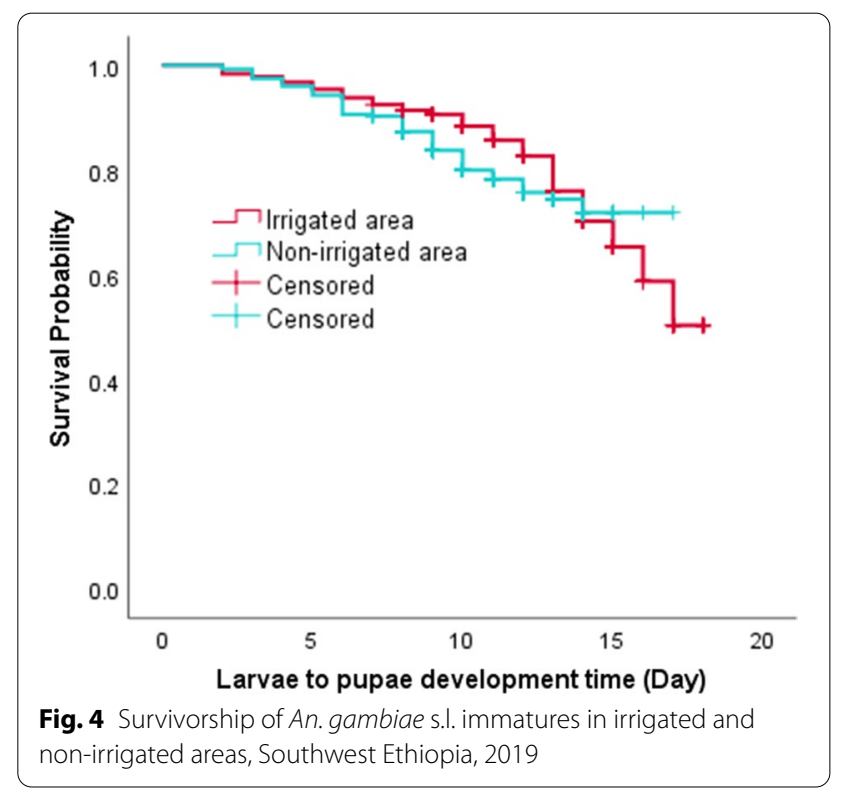


Table 2 Stage-specific survivorship and mortality rate of immature An. gambiae s.l. in the irrigated area, Southwest Ethiopia, 2019

\begin{tabular}{|c|c|c|c|c|c|c|}
\hline \multirow[t]{2}{*}{ Stage } & \multicolumn{3}{|l|}{ Irrigated area } & \multicolumn{3}{|l|}{ Non-irrigated area } \\
\hline & $\begin{array}{l}\text { Development time } \\
\text { (day) }\end{array}$ & $\begin{array}{l}\text { Cumulative survival } \\
\text { rate }\end{array}$ & $\begin{array}{l}\text { Stage mortality } \\
\text { rate }\end{array}$ & $\begin{array}{l}\text { Development time } \\
\text { (day) }\end{array}$ & $\begin{array}{l}\text { Cumulative survival } \\
\text { rate }\end{array}$ & $\begin{array}{l}\text { Stage } \\
\text { mortality } \\
\text { rate }\end{array}$ \\
\hline 1st Instar & 2.3 & 0.98 & 0.02 & 2.1 & 0.98 & 0.03 \\
\hline 2nd Instar & 2.5 & 0.96 & 0.03 & 2.4 & 0.95 & 0.03 \\
\hline 3rd Instar & 4.6 & 0.92 & 0.04 & 3.5 & 0.89 & 0.06 \\
\hline 4th Instar & 5.1 & 0.79 & 0.19 & 4.5 & 0.84 & 0.09 \\
\hline
\end{tabular}

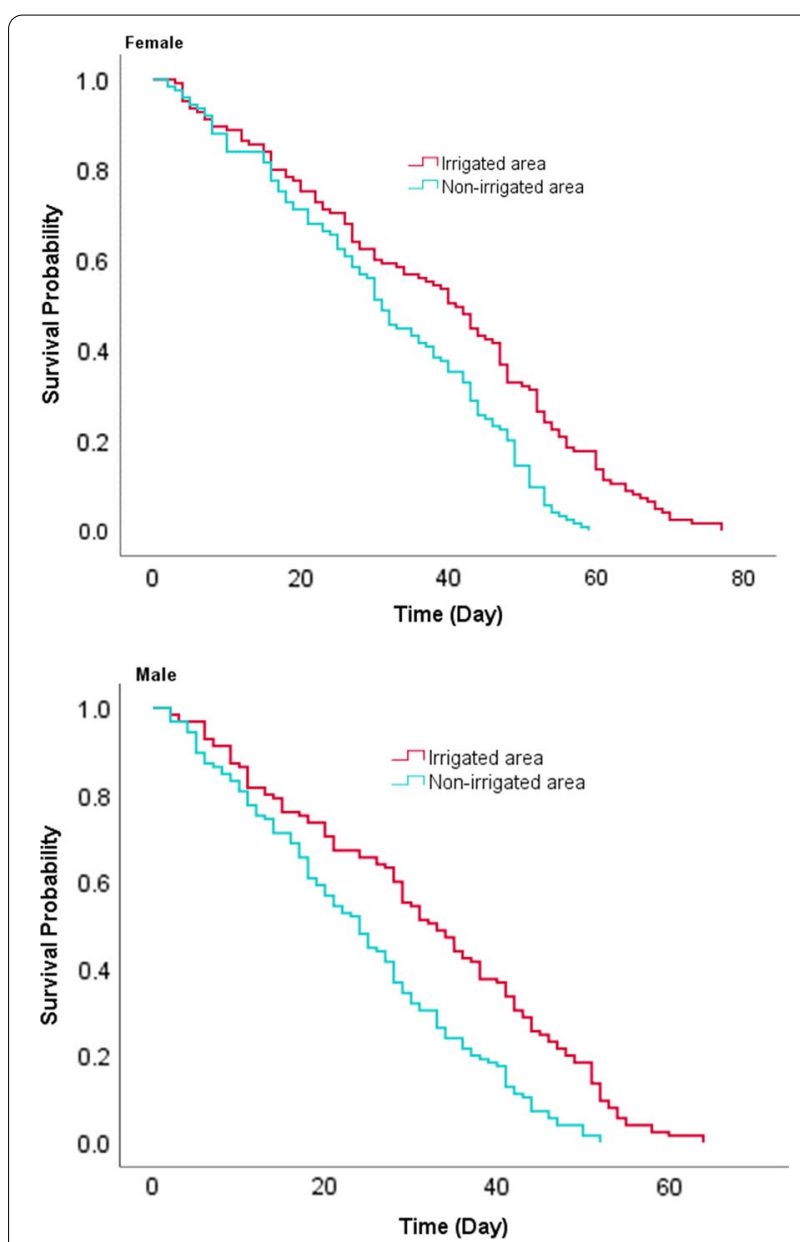

Fig. 5 Survivorship of adult An. gambiae s.l. in irrigated and non-irrigated areas, Southwest Ethiopia, 2019

\section{Aquatic habitat microclimate during larval survivorship experiment}

An independent sample t-test analysis on microclimate differences between the two study settings indicated that mean hourly water temperature $\left({ }^{\circ} \mathrm{C}\right)$ in washbasins placed at the non-irrigated area was $1.1{ }^{\circ} \mathrm{C}$ higher than in washbasins in the irrigated area $(t=-2.85, P$ $=0.004)$. Similarly, mean light intensity (lum/ft2) in the non-irrigated area (mean $=497.4 \pm 982.2$ ) was significantly higher than in the irrigated area (mean $=372.7 \pm$ 664.8), $(t=-2.47, P=0.014)$ (Table 4 and Fig. 6). Mean maximum and minimum temperature and light intensity were also significantly higher in washbasins in the nonirrigated area compared to the irrigated area (Table 4).

\section{Ambient microclimate during adult survivorship experiment}

There was no significant difference in ambient hourly average, maximum and minimum temperature and relative humidity between the irrigated area and non-irrigated area. However, mean light intensity between the two sites was different $(P=0.001)$ (Table 5 and Fig. 7).

\section{Discussion}

In this study, we investigated the effects of environmental modification on the development, survivorship, and fecundity of malaria vector mosquitoes. We hypothesized that irrigated sugarcane plantation areas enhance development, survivorship, and fecundity compared to nonirrigated field crop areas because of better microclimates and nutrients following environmental modification. However, the study showed no significant difference in

Table 3 Means and medians of survival time for adult An. gambiae s.l. in irrigated and non-irrigated areas, Southwest Ethiopia, 2019

\begin{tabular}{|c|c|c|c|c|}
\hline \multirow[t]{2}{*}{ Site } & \multicolumn{2}{|c|}{ Female Anopheles gambiae } & \multicolumn{2}{|c|}{ Male Anopheles gambiae } \\
\hline & Mean with $95 \% \mathrm{Cl}$ & Median with 95\% Cl & Mean with $95 \% \mathrm{Cl}$ & Median with $95 \% \mathrm{Cl}$ \\
\hline Irrigated area & $37.9(34.8-41.5)$ & $41.0(35.9-46.1)$ & $31.8(28.9-34.7)$ & $33.0(28.3-37.7)$ \\
\hline Non-irrigated area & $31.3(28.5-34.1)$ & $31.0(27.9-34.1)$ & $24.2(21.8-26.6)$ & $24.0(20.3-27.6)$ \\
\hline
\end{tabular}


Table 4 Mean hourly temperature and light intensity in washbasins in the irrigated and non-irrigated areas, Southwest Ethiopia, 2019

\begin{tabular}{|c|c|c|c|c|c|}
\hline Microclimate & Irrigated area $(\mathrm{M} \pm \mathrm{SE})$ & Non-irrigated area $(\mathrm{M} \pm \mathrm{SE})$ & $t$ & $d f$ & $P$ \\
\hline Mean temperature $\left({ }^{\circ} \mathrm{C}\right)$ & $23.3 \pm 5.7$ & $24.4 \pm 6.3$ & -2.85 & 1068 & 0.004 \\
\hline Mean maximum temperature $\left({ }^{\circ} \mathrm{C}\right)$ & $24.4 \pm 6.5$ & $25.4 \pm 7.2$ & -2.53 & 1068 & 0.012 \\
\hline Mean minimum temperature $\left({ }^{\circ} \mathrm{C}\right)$ & $22.5 \pm 5.1$ & $23.4 \pm 5.4$ & -2.83 & 1068 & 0.005 \\
\hline Mean light intensity (lum/ft²) & $372.7 \pm 664.8$ & $497.4 \pm 982.2$ & -2.47 & 1068 & 0.014 \\
\hline Mean maximum light intensity (lum/ $\left.\mathrm{ft}^{2}\right)$ & $713.0 \pm 1311.7$ & $931.0 \pm 1698.0$ & -2.28 & 1068 & 0.018 \\
\hline Mean minimum light intensity (lum/ft²) & $174.4 \pm 311.9$ & $229.1 \pm 495.5$ & -2.21 & 1068 & 0.027 \\
\hline
\end{tabular}

$M \pm S E:$ mean \pm standard error

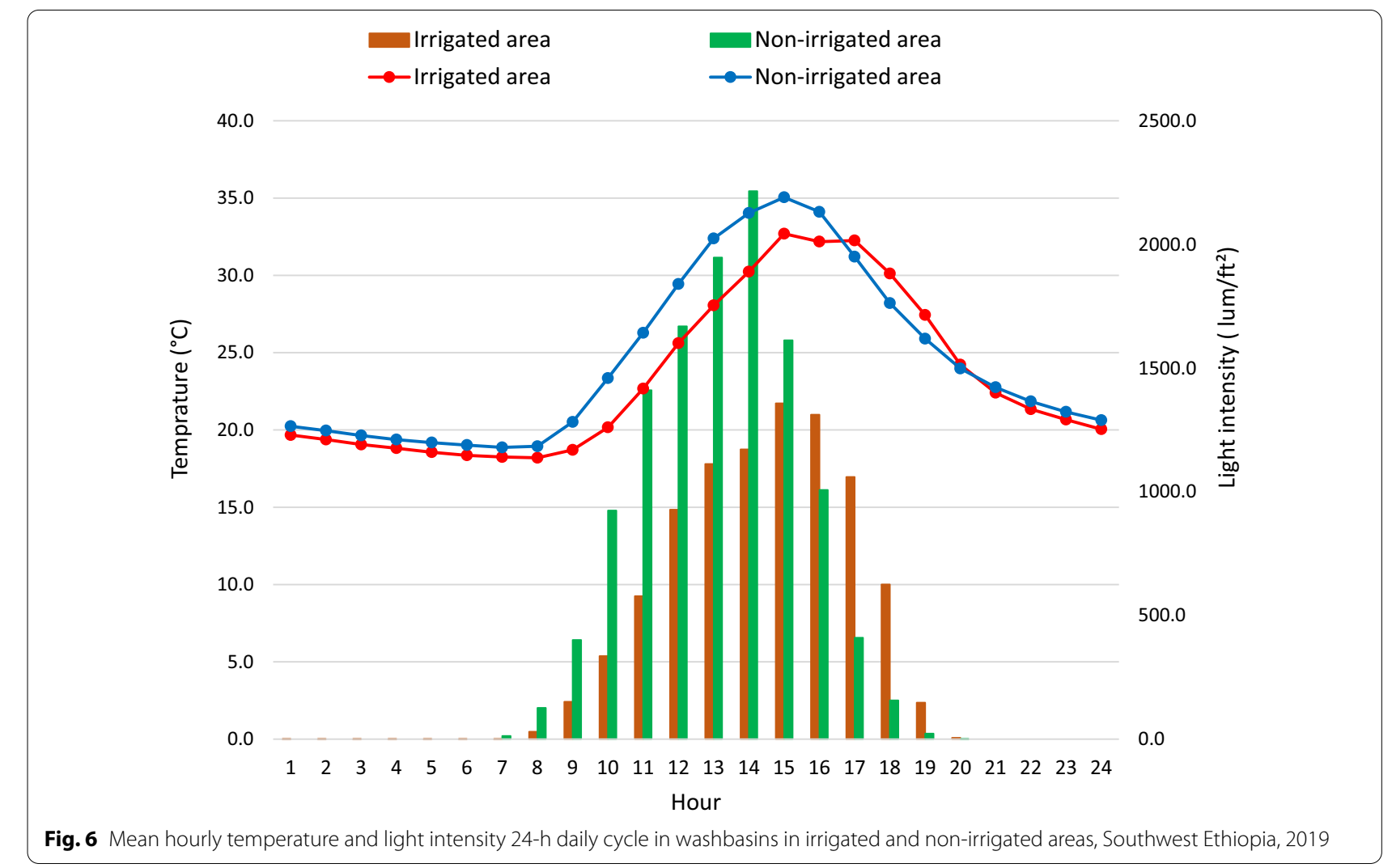

Table 5 Hourly microclimate condition of mosquito niches in irrigated and non-irrigated areas, Southwest Ethiopia, 2019

\begin{tabular}{|c|c|c|c|c|c|}
\hline Microclimate & Irrigated area $(\mathrm{M} \pm \mathrm{SE})$ & Non-irrigated area ( $\mathrm{M} \pm \mathrm{SE})$ & $t$ & $d f$ & $P$ \\
\hline Mean temperature $\left({ }^{\circ} \mathrm{C}\right)$ & $21.56 \pm 4.80$ & $21.60 \pm 4.81$ & -0.26 & 3176 & 0.790 \\
\hline Mean maximum temperature $\left({ }^{\circ} \mathrm{C}\right)$ & $22.22 \pm 5.09$ & $22.24 \pm 5.10$ & -0.09 & 3176 & 0.927 \\
\hline Mean minimum temperature $\left({ }^{\circ} \mathrm{C}\right)$ & $20.90 \pm 4.56$ & $20.92 \pm 4.56$ & -0.12 & 3176 & 0.904 \\
\hline Mean relative humidity (\%) & $82.65 \pm 15.73$ & $82.30 \pm 14.58$ & -0.63 & 3176 & 0.522 \\
\hline Mean maximum relative humidity (\%) & $86.11 \pm 13.77$ & $86.55 \pm 11.80$ & -0.92 & 3176 & 0.339 \\
\hline Mean minimum relative humidity (\%) & $78.95 \pm 17.78$ & $78.12 \pm 17.23$ & 1.31 & 3176 & 0.187 \\
\hline Mean light intensity (lum/ft²) & $324.3 \pm 517.5$ & $709.0 \pm 1242.3$ & -11.7 & 2952 & 0.001 \\
\hline Mean maximum light intensity $\left(\mathrm{lum} / \mathrm{ft}^{2}\right)$ & $571.7 \pm 982.5$ & $1106.8 \pm 1834$ & -10.3 & 2952 & 0.001 \\
\hline Mean minimum light intensity (lum/ft²) & $180.1 \pm 267.5$ & $366.6 \pm 663.4$ & -10.7 & 2952 & 0.001 \\
\hline
\end{tabular}




\section{Irrigated area Non-irrigaed area \\ $\rightarrow$ - Irrigated area $\quad \longrightarrow$ Non-irrigaed area}

35.00

120.00

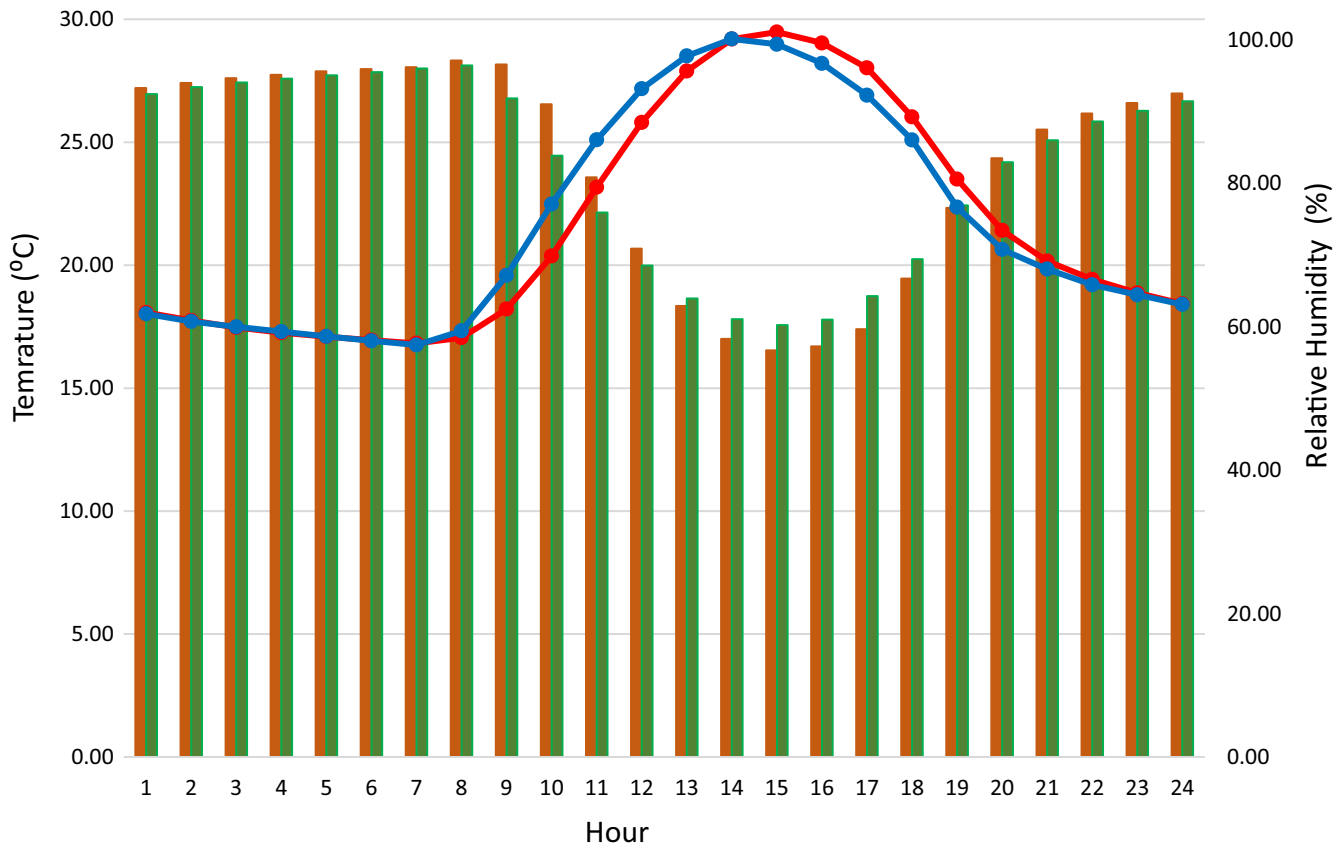

Fig. 7 Mean hourly ambient temperature and relative humidity 24-h daily cycle in irrigated and non-irrigated areas, Southwest Ethiopia, 2019

development and survivorship of An. gambiae s.l. immatures between the two areas.

Variation in vegetation cover may affect the radiation flux and energy balance off the land surface and thus may modify the microclimate [25]. By the time the experiment was conducted, sugarcane plantation was at its maturity stage, which is dense and leafy, which could partly limit direct sunlight from reaching the washbasins, whereas in the surrounding crops the field areas were relatively less dense. The mean hourly water temperature in the non-irrigated area increased by $1.1{ }^{\circ} \mathrm{C}$ compared to the irrigated area. This could partly explain the observed $5.1 \%$ greater pupation rate in the non-irrigated area compared to the irrigated area. Studies reported elsewhere indicated that increased temperature due to land use and land cover increased the larval survival rate [10, 26-30]. Tuno et al. [29] reported that the survivorship of $A n$. gambiae larvae was reduced from $56 \%$ in habitats fully exposed to sunlight to $1.5 \%$ in habitats with forest canopy in western Kenya. Wang et al. [10] also reported the pupation rate of An. minimus, a malaria vector in China, to be $52.5 \%, 12.5 \%$, and $3.8 \%$ in the deforested, banana plantation, and forested areas, respectively, which is far lower than our findings of $79.4 \%$ and $84.5 \%$ at the irrigated and non-irrigated areas, respectively.

Nutrient availability may affect the survival, pupation rate, and development time. The potential food source of anopheline larvae may include but not be limited to bacteria, fungi, debris, and organic matter. The abundance and structure of microbes such as algae and photosynthetic cyanobacteria in aquatic habitats may have changed in response to land use and land cover [31, 32]. Organic matter and debris in the soil at different settings may not be the same, which could possibly vary with changes in the surrounding land use and land cover. Kebede et al. [33] reported that maize pollen provides nutrition for larval anopheline mosquitoes showing that the incidence of malaria was about ten times higher in high maize cultivation areas. In our case, the debris of sugarcane plantation and other field crops might not be the same but the result showed both areas support mosquito development, which needs further investigation of soils' biological and chemical composition in relation to immature mosquito development.

The higher pupation rate and longer survivorship of $A n$. gambiae s.l. immatures generally could increase vectorial 
capacity to enhance malaria transmission. Based on these findings alone, we cannot conclude that the irrigated area encounters less or equal malaria risk compared to the surrounding environs. Recently, in a study conducted from the same area, significantly more diverse breeding sites and larva abundance have been reported in irrigated sugarcane plantation areas than in their surroundings [23]. Thus, more diversified breeding sites with a $79.4 \%$ pupation rate could certainly outweigh the malaria burden over surrounding environs with less habitat diversity and relatively the same pupation rate.

Adult An. gambiae s.l. placed in the irrigated area survived longer than those in a non-irrigated area. Adult female mosquitoes survived longer than males in both settings. Our findings of mosquito longevity were in line with previous studies elsewhere. For instance, Okech et al. [34], reported mean survival of 33 days for An. gambiae s.l. in western Kenya, which is 6 days shorter than our finding. Gary and Forster [35] found that An. gambiae s.l. mosquitoes had a median survival time of 29 days under insectary conditions, but in our study, the median survival time for female An. gambiae s.l. was 41 and 31 days in the irrigated and non-irrigated area, respectively. The longer survival of mosquitoes in the irrigated area indicates that $A n$. gambiae s.l. is well adapted to the environmental conditions. Enhanced survival of malaria vectors is among the determinants of increased mosquito vectorial capacity [36]. A long life of an adult female mosquito increases her opportunities to encounter an infected human host and the extrinsic incubation period of malaria parasites so that they can reach the salivary glands after an infective bloodmeal and be transmitted in later bloodmeals to uninfected hosts [1, 3, 37]. This has implications for malaria transmission at the locality.

The experimental set-up at both study settings were the same, and human blood and sugar were provided in a similar way. Thus, the only difference was the environment where the experiments were situated, being an irrigated and non-irrigated area. There was no significant difference in mean, maximum, and minimum hourly ambient temperature and relative humidity between the two environments. Previous studies indicated that $A n$. arabiensis, a primary vector in Ethiopia, generally prefers areas with low humidity and high temperature [38]. A similar study also demonstrated that reduced humidity and increased temperatures following deforestation create a more suitable environment for adult $A n$. arabiensis to survive longer [26]. Therefore, in our study setting the determinants involved in supporting better survival of adult An. gambiae s.l. at the irrigated area warrants further investigation.

The average daily fecundity of An. gambiae s.l. mosquitoes in the irrigated area was $96.2 \%$ higher compared to the non-irrigated area. Increased survival together with enhanced fecundity of malaria vectors in the irrigated area suggests that the longevity and biotic potential of An. gambiae s.l. in the area are very high, favoring increased population density, and thus the species could contribute greatly to malaria transmission. Better survival and fecundity in the irrigated area in our study are in agreement with the study conducted in Ethiopia at the laboratory level demonstrating that gravid $A n$. arabiensis females were attracted to sugarcane pollen volatiles [39].

This study had several limitations. The experiment was done at one time point of the maturity stage of the irrigated sugarcane area. The microclimate conditions in the irrigated area during the seedling/germinating stage, tillering stage, grand growth stage, and maturity stage [40] could not be the same, which in turn influenced the mosquito survivorship. Information on the chemical and nutrient composition of the soil used as a substrate was not included in the study. Moreover, the experiments were conducted under controlled conditions for all potential biological factors that may influence mosquito survival, such as predators and competitors, which might lead to an overestimation of the survival time compared to the actual time.

\section{Conclusion}

Irrigated sugarcane plantation significantly enhances the survivorship and fecundity of adult An. gambiae s.l., the major malaria vector in Ethiopia. The study results on survivorship parameters of malaria vector mosquitoes under a variety of environmental conditions are helpful to model the impact of environmental modification on vector population dynamics and help devise tailor-made vector control strategies. Moreover, longer survivorship of adult mosquitoes in irrigated areas calls for larval management to reduce the vector population and subsequent malaria transmission.

\section{Supplementary Information}

The online version contains supplementary material available at https://doi. org/10.1186/s13071-021-04630-8.

Additional file 1: Survivorship comparison of adult male and female An. gambiae s.l. in irrigated and non-irrigated areas, Southwest Ethiopia, 2019.

Additional file 2: Mean eggs laid per mosquito in irrigated and nonirrigated areas, Southwest Ethiopia, 2019.

\section{Acknowledgements}

Jimma University, Tropical and Infectious Diseases Research Center (JU-TIDRC), is duly acknowledged for facilitating the study. We thank the Arjo-Dedessa Sugar Development Project office for the permission to conduct the study in the area. The anonymous reviewers are thanked for their comments on an earlier version of the paper. 


\section{Authors' contributions}

$\mathrm{DH}$ conceived the study; conducted experiment; performed data analysis; interpreted data and drafted a manuscript. DB participated in data analysis. AD and AT participated in data acquisition. DY, SK, and GY critically reviewed the manuscript for important intellectual content. All authors read and approved the final manuscript

\section{Funding}

This study was financially supported by grants from the National Institutes of Health (NIH) (D43 TW001505, R01 A1050243, and U19 Al129326). The funders had no role in the study design, data acquisition and analysis, decision to publish, or preparation of the manuscript.

\section{Availability of data and materials}

The datasets used and/or analysed during the current study are available from the corresponding author on reasonable request.

\section{Ethics approval and consent to participate}

Ethical clearance was obtained from the Institutional Review Board (IRB) of Institute of Health, Jimma University, National Ethics Review Committee (NERC) of Ethiopia, and University of California, Irvine, CA, USA. The study did not involve any endangered or protected species.

\section{Consent for publication}

Not applicable.

\section{Competing interests}

The authors declare that they have no competing interests.

\section{Author details}

${ }^{1}$ Yirgalem Hospital Medical College, Yirgalem, Ethiopia. ${ }^{2}$ Department of Medical Laboratory Sciences, College of Medicine and Health Sciences, Ambo University, Ambo, Ethiopia. ${ }^{3}$ Program in Public Health, University of California at Irvine, Irvine, CA 92697, USA. ${ }^{4}$ Department of Medical Laboratory Sciences and Pathology, Institute of Health, Jimma University, Jimma, Ethiopia. ${ }^{5}$ Department of Biology, Collage of Natural Science, Jimma University, Jimma, Ethiopia. ${ }^{6}$ Tropical and Infectious Diseases Research Center (TIDRC), Jimma University, Jimma, Ethiopia. ${ }^{7}$ Department of Statistics, College of Science, Bahir Dar University, Bahir Dar, Ethiopia.

Received: 27 November 2020 Accepted: 6 February 2021 Published online: 06 March 2021

\section{Reference}

1. Garrett-Jone C. Prognosis for interruption of malaria transmission through assessment of the mosquito's vectorial capacity. Nature. 1964;204:1173-5.

2. Ohm JR, Baldini F, Barreaux P, Lefevre T, Lynch PA, Suh E, et al. Rethinking the extrinsic incubation period of malaria parasites. Parasit Vectors. 2018:11:178.

3. Edalat H, Hassan Moosa-Kazemi S, Abolghasemi E, Khairandish S, Hassan M-K. Vectorial capacity and Age determination of Anopheles Stephens Liston (Diptera: Culicidae), during the malaria transmission in Southern Iran. J Entomol Zool. 2015:3:256-63.

4. Paaijmans KP, Imbahale SS, Thomas MB, Takken W. Relevant microclimate for determining the development rate of malaria mosquitoes and possible implications of climate change. Malar J. 2010;9:196.

5. Paaijmans KP, Thomas MB. The influence of mosquito resting behaviour and associated microclimate for malaria risk. Malar J. 2011;10:183.

6. Sonora US, Border MX, Hayden MH, Uejio CK, Walker K, Ramberg F, et al. Microclimate and Human Factors in the Divergent Ecology of Aedes aegypti Microclimate and Human Factors in the Divergent Ecology of Aedes aegypti along the Arizona. EcoHealth. 2010;7:64-77.

7. Singer $\mathrm{BH}$, Utzinger $J$. Effect of irrigation and large dams on the burden of malaria on a global and regional scale. Am J Trop Med Hyg. 2005;72:392-406

8. Sternberg ED, Thomas MB. Local adaptation to temperature and the implications for vector-borne diseases. Trends Parasitol. 2014;1258:1-8.

9. Zhong D, Wang X, Xu T, Zhou G, Wang Y. Effects of Microclimate Condition Changes Due to Land Use and Land Cover Changes on the
Survivorship of Malaria Vectors in China- Myanmar Border Region. PLoS ONE. 2016;11:e015530.

10. Wang X, Zhou G, Zhong D, Wang X, Wang Y, Yang Z, et al. Life-table studies revealed significant effects of deforestation on the development and survivorship of Anopheles minimus larvae. Parasit Vectors. 2016;9:323.

11. Murdock CC, Evans MV, Mcclanahan TD, Miazgowicz L, Tesla B. Fine-scale variation in microclimate across an urban landscape shapes variation in mosquito population dynamics and the potential of Aedes albopictus to transmit arboviral disease. PLoS Negl Trop Dis. 2017;11:e0005640.

12. Haile GG. Irrigation in Ethiopia, a Review. J Environ Earth Sci. 2015:5:141-8

13. Kibret $\mathrm{S}$, Wilson GG, Ryder D, Tekie H, Petros B. The Influence of Dams on Malaria Transmission in Sub-Saharan Africa. EcoHealth. 2017;14:408-19.

14. Yewhalaw D, Legesse W, Van BW, Gebre- S, Kloos H, Duchateau L, et al. Malaria and water resource development : the case of Gilgel-Gibe hydroelectric dam in Ethiopia. Malar J. 2009;8:21.

15. Kibret S, Alemu Y, Boelee E, Tekie H, Alemu D, Petros B. The impact of a small-scale irrigation scheme on malaria transmission in Ziway area. Central Ethiopia Trop Med Int Heal. 2010;15:41-50.

16. Mutero CM, Kabutha C, Kimani V, Kabuage L, Gitau G, Ssennyonga J, et al. A transdisciplinary perspective on the links between malaria and agroecosystems in Kenya. Acta Trop. 2004;89:171-86.

17. Kibret S, Wilson GG, Ryder D, Tekie H, Petros B. Malaria impact of large dams at different eco-epidemiological settings in Ethiopia. Trop Med Heal. 2017:45:1-14.

18. Yohannes M, Haile M, Ghebreyesus TA, Witten KH, Getachew A, Byass $P$, et al. Can source reduction of mosquito larval habitat reduce malaria transmission in Tigray, Ethiopia? Trop Med Int Heal. 2005;10:1274-85.

19. Yewhalaw D, Getachew Y, Tushune $K$, et al. The effect of dams and seasons on malaria incidence and Anopheles abundance in Ethiopia. BMC Inf Dis. 2013;13:161.

20. Ayele DG, Zewotir TT, Mwambi HG. Prevalence and risk factors of malaria in Ethiopia. Malar J. 2012;11:195.

21. Kibret S, Lautze J, Mccartney M, Nhamo L, Wilson GG. Malaria and large dams in sub-Saharan Africa : future impacts in a changing climate. Malar J. 2016;15:448.

22. Hawaria D, Getachew H, Zhong G, Demissew A, Habitamu K, Raya B. Ten years malaria trend at Arjo - Didessa sugar development site and its vicinity, Southwest Ethiopia : a retrospective study. Malar J. 2019;18:145.

23. Hawaria D, Demissew A, Kibret S, Lee M, Yewhalaw D, et al. Effects of environmental modification on the diversity and positivity of anopheline mosquito aquatic habitats at Arjo-Dedessa irrigation development site. Southwest Ethiopia Infect Dis Poverty. 2020;9:9.

24. Taffere GR. Malaria elimination plan by 2030 in Ethiopia: Does evidencebased practice matter? A J Immu. 2018;8:3-12.

25. Duveiller $\mathrm{G}$, Hooker J, Cescatti A. The mark of vegetation change on Earth's surface energy balance. Nat Commun. 2018;9:679.

26. Afrane YAWA, Zhou G, Lawson BW, Githeko AK, Yan G. Effects of microclimatic changes caused by deforestation on the survivorship and reproductive fitness of anopheles gambiae in Western Kenya highlands. Am J Trop Med Hyg. 2006;74:772-8.

27. Afrane YA, Little TJ, Lawson BW, Githeko AK, Yan G. Deforestation and Vectorial Capacity of Anopheles gambiae Giles Mosquitoes in Malaria. Emerg Infec Dis. 2008;14:1533-8.

28. Kweka EJ, Kimaro EE, Munga S, Veleeparambil MM. Effect of deforestation and land use changes on mosquito productivity and development in Western Kenya Highlands: Implication for malaria risk. Front public $\mathrm{H}$. 2016;4:238.

29. Tuno N, Okeka W, Minakawa N, Takagi M. Survivorship of Anopheles gambiae sensu stricto ( Diptera : Culicidae ) Larvae in Western Kenya Highland Forest. J Med Entomol. 2005;42:270-7.

30. Mwangangi JM, Muturi EJ, Shililu J, Muriu SM, Jacob B, Kabiru EW, et al. Survival of immature Anopheles arabiensis ( Diptera: Culicidae) in aquatic habitats in Mwea rice irrigation scheme, central Kenya. Malar J. 2006;5:114

31. Wang Y, Gilbreath 3rd TM, Kukutla P, Yan G XJ. Dynamic gut microbiome Kenya, across life history of the malaria mosquito Anopheles gambiae. PLoS One. 2011;6:e24767.

32. Kaufman MG, Wanja E, Maknojia S, Bayoh MN, Vulule JM, Walker EDI. Importance of algal biomass to growth and development of Anopheles gambiae larvae. J Med Entomol. 2006;43:669-76. 
33. Kebede A, Cann JCMC, Kiszewski AE, Ye-ebiyo Y. New evidence of effects of agro-ecological change on malaria transmission. Am J Trop Med Hyg. 2005;73:676-80.

34. Okech BA, Gouagna LC, Killeen GF, Knols BGKE, Beier JC, Yan GGJ. Influence of sugar availability and indoor microclimate on survival of Anopheles gambiae (Diptera: Culicidae) under semifield conditions in western Kenya. J Med Entomol. 2003:40:657-63.

35. Gary REJ, Foster WA. Effects of available sugar on the Vector, reproductive fitness and vectorial capacity of the malaria Entomol, Anopheles gambiae (Diptera: Culicidae). J Med Entomol. 2001;38:22-8.

36. McDonald G. The Epidemiology and Control of Malaria. London: London:Oxford University Press.: Oxford University Press.; 1957.

37. Olayemi IKAA. Survivorship of Anopheles gambiae in relation to malaria transmission in Ilorin. Nigeria J Heal Allied Sci. 2008;7:1-5.

38. Colluzi M, Sabatini A, Petrarca V, Di Deco MA. Chromosomal differentiation and adaptation to human environments in the Anopheles gambiae complex. Trans R Soc Trop Med Hyg. 1979;73:483-97.
39. Wondwosen B, Birgersson G, Tekie H, Torto B, Ignell R, Hill SR. Sweet attraction : sugarcane pollen-associated volatiles attract gravid Anopheles arabiensis. Malar J. 2018;17:90

40. Gunnula W, Righetti T. Evaluating sugarcane growth and maturity using ground-based measurements and remote sensing data evaluating sugarcane growth and maturity using ground-based measurements and remote sensing data. Thai J Agr Sci. 2012;45:17-28.

\section{Publisher's Note}

Springer Nature remains neutral with regard to jurisdictional claims in published maps and institutional affiliations. 